\section{Body, Habit, Custom and Labour}

Shriddha Shah'
Social Change

$47(2) 189-199$

(C) CSD 2017

SAGE Publications

sagepub.in/home.nav

DOI: $10.1177 / 00490857|769639|$

http://sch.sagepub.com

\begin{abstract}
Theories in the modern age in philosophy, as well as in the discourse of the social sciences, are pervaded with the presuppositions of the dualisms of mind and world, theory and practice, private and public. These theoretical dualisms make it impossible to have an account of the interconnected nature of the experience of individuals and societies. The philosophical theoretical vocabulary to take account of the relations between these dualisms has been effaced with the legacy of Cartesian dualism. I argue that through a conceptual analysis of the body, as has been posited by Maurice Merleau-Ponty, and the related concepts of habit, custom and labour, we can reclaim some concepts that allow a mediation of these dualisms. In this article, I make a conceptual analysis of the epistemic, metaphysical and social-political interrelations between these concepts and argue for the relational role they play in our philosophical theoretical discourse.
\end{abstract}

\title{
Keywords
}

Body, Cartesian dualism, self, habit, custom, labour, dialectic

The advent of modernity in western civilisation is marked by the rise of the positivist methodology and the presuppositions of dualism that pervade our theoretical discourse, whether it is mind and world, theory and practice, private and public or any other. The key issue is the effacement of the theoretical possibility of a relation between these various dualisms with the rise of the positivist methodology. It is in this context that I discuss the epistemic, metaphysical and social-political interrelations between the concepts of the body, habit, custom and labour. I argue that these are terms that manifest the nature of the relation between the human person, nature and the other/s, and it is this relation that allows us to mediate the dualisms that pervade our theoretical discourse and have an understanding of the human self and also the shared world.

' Department of Philosophy, Faculty of Arts, University of Delhi, New Delhi, India.

\section{Corresponding author:}

Shriddha Shah, Department of Philosophy, Faculty of Arts, University of Delhi, New Delhi I I0007, India.

Email: shriddhashah@gmail.com 
Much of the contemporary philosophical discussion on the body rests on the presupposition of the Cartesian mind and world dualism that marks the onset of modern philosophical thought. The defining influence of this dualism has been such that despite all the discussion on the implications of mind-body dualism, its presuppositions pervade our theoretical discourse, and thereby relegate the body and all the concepts associated with it, such as pain, labour, habits, customs to the linear and mechanical cycle of cause and effect. The consequence of this is that we either engage with our human condition as disembodied abstract beings or with the body as a mechanical material entity, open to manipulation and external control. Theoretically, the possibility of a self/subject in dialectical relation of mutual interchange with the objective world is lost. In theory, either the self is passively determined by the world or it is completely closed in on itself and its solipsistic mechanisms, without the mark of an objective relation with the world. The theoretical possibility of the self to be in relation with the world and yet have volition is lost in the dualist discourse.

It is in this respect that this article seeks to articulate the key theoretical role played by the body with respect to habits, customs and labour, in mediating the relation between not only the self and the world, but also the body and the body politic. I argue that the mediation of these relations is not dependent merely on the ontological constitution of the body but on the role of reflection in negotiating these relations. The body is a much-discussed issue in contemporary philosophical scholarship, especially in light of the work of Maurice Merleau-Ponty (1962). Merleau-Ponty's phenomenological discussion of the body provides me with a position where the body can be discussed as the medium between the self and the world. However, the objective in this article is not only to discuss the body as a medium or sign of the relation between self and the world and the body and the body politic, but also to discuss the specific role of reflection in orchestrating this relation, that is, the relation between the metaphysical and ontological constitution of the body and the body politic and the role of epistemology in negotiating this relationship. In this regard, Felix Ravaisson's (2008) discussion of habit allows me to show the relation between the ontological and epistemological aspects of habit, which is also clarified through David Hume's (1979) discussion of the epistemological role of custom and habit. It is this connection between the epistemic and metaphysical which is brought to bear upon the social and political realm, in Marx's articulation of the body in labour as a sign of the relation between the body and the body politic.

\section{The Concept of the Body}

Maurice Merleau-Ponty is perhaps one of the most prominent philosophers who locates the body as the centre of the discourse in terms of transcending the subjectobject dichotomy. His phenomenological analysis of perception in Phenomenology of Perception (1962), articulates the special role played by the body in perception and thereby also in the understanding of human knowledge. This problem of understanding the role of the body is located in the dualist discourse, where either 
the material world or the world of thought is privileged over the lived embodied experience in the world.

Merleau-Ponty considers the body as the condition for perception. The body as the basis of our perspective upon the world, conditions all our experiences. For an object to appear into view it must conceal some other object. This is the very nature of an object according to him, and it is not dependent on the contingent understanding of our bodily make-up (the structure of eyes, its composition of rods and cones). The object-horizon structure is what constitutes perspective. To see an object is to enter into a world where the object can be hidden behind something or myself, and this is what allows an object to display itself. To be able to distinguish and focus on an object, it must be distinguished against a horizon. He explains further, for instance, when we view an object we ascribe to it qualities not only the ones that are visible to us but also that are 'visible' to other objects in the vicinity. Objects thus present themselves as forming a system or a world. The permanence and identity of an object is granted in a system or a world, and the object itself is the object seen from everywhere (Merleau-Ponty, 1962, pp. 67-69). The thrust of this formulation is not to hint at the conformity with others in terms of perception but in fact the very opposite - the uniqueness of each perspective, and further and more fundamentally, to articulate the metaphysical and ontological conditions of perception - relation of the self and the other/s in the constitution of an object in perception.

He further argues that the above account made in terms of the spatiality of an object is applicable to the temporal aspect of it as well. The present moment when an object is viewed is a moment in its temporal duration. Despite the changes in the object each moment underpins a permanent reality. Each moment calls forth the other moments to bear witness to the object as it is in the present, and thereby in a sense contains the possibility of how things will turn out. This is ensured through the same structure of the horizon. The present holds on to the immediate past and likewise the immediate past bears the same relation with its past. The impending future holds the horizon of imminence. The present will be the immediate past of that imminent future and thus, there is an ongoing flow of duration, where the horizon directs our gaze to the past as well as to the possible and imminent future (Merleau-Ponty, 1962, p. 69).

His discussion on embodiment highlights that any object in our perception is constituted by us and is not naturally given. This constitution of the object is dependent on the condition of embodiment and the perspective that it allows us on to the world. This world is not a subjective personal world but a world which comprises and is understood against the horizon of other beings and objects existent in this world. The body then is our locus and the medium via which we interact and constitute the world and our worldview.

The key argument for my project is Merleau-Ponty's articulation of the nature of the body, wherein it is conceived of as consisting of two layers - the habit body and the body at this moment. The body then is not to be apprehended only as revealed to us at this moment but in the light of a more general aspect and of an 'impersonal being'. The notion of the impersonal being is a very crucial concept as it is this notion that allows the transcendence of the mind and world dualist 
options for the understanding of the body. The body need not be limited to our immediate experience of it and in fact despite its particularity, it is also the only tool that which allows us to transcend that particularity. Merleau-Ponty points out that under most cases we take recourse to our immediate body and personal existence, but at the margins of our existence there exist patterns and rhythms that arise out of our interactions with other human beings and the world, almost akin to a kind of impersonal existence, and it is this horizon which allows us to carry on with our lives and enclose our personal spaces within that (Merleau-Ponty, 1962, p. 82).

Thus, there is a sort of dialectic that plays out between this personal and impersonal existence. In this sense, the body serves as the pivot on which this interplay occurs and our existence is centred on but it also prevents it from being centred completely. This ambiguity is the peculiarity of the role of the body and our existence in the world. Thus, according to him the contentious union of the soul and the body is not something brought about by arbitrary decree but is a matter of enactment in every moment of existence where personal and impersonal being are both involved (Merleau-Ponty, 1962, p. 89).

\section{Habit, Custom and Labour and their Interrelations}

It is this articulation of the nature of the body that allows me to take account of habits and customs. These patterns of interaction indicate the role of the body as the medium through which there is interaction between not only the self and the world but also the body and the body politic. The body is the site for these patterns of interaction to take hold whether it is personal habits or customs of the body politic; it is these patterns of interaction with the body as the pivotal site that indicate mediation between the mind and the world and also the public and the private.

These patterns of interaction assume repetition and repetition as a fundamental law, whereby it is constitutive of the basic conditions of human nature and existence. However, this repetition is not merely mechanical as is commonly held in the modern western philosophical tradition. Habit as a term is also generally considered derogatory in this discourse. This is a part of the legacy of Cartesian and Kantian philosophy where habit is considered merely a mechanical repetition stifling the reflective freedom of the mind and thereby the cause of inauthentic living (Malabou, 2008, p. vii). Despite the fact that David Hume calls habit or custom the great guide of human life (Hume, 1979, p. 44), habit as a concept of central philosophical importance has not received due consideration. In the last century only some pragmatic and continental philosophers have given the concept some attention, but it has not found its way into the discourse of mainstream contemporary philosophy. As stated, in part, this is due to the legacy of Descartes and Kant, but more importantly it is my contention that the legacy is due to the dominance of the positivist methodology in modern western philosophy, which cannot account for concepts that explicate relations. Habit as a concept is what allows the self to mediate the relation between the immediate/personal and the impersonal self, and therefore escapes articulation within modern western philosophy. 
The crucial issue is that in the conception of habit as a relation there are always two sides which can be distinguished but cannot be separated and thus there is a dialectical interplay, the course of which is determined by the self.

David Hume, on the other hand, considers habit or custom as the great guide of human life. In explicating this argument, the epistemic aspect of habit is quite clear. It is what allows human knowledge to surpass the hold of immediate influence of the senses and memory and thereby allows us to make experience useful as a source of action in the present and for the future. The temporal aspect of custom or habit, where past experience is brought on to bear on present experience and thereby be a source of action, is what maintains continuity for the human being and his identity and also serves as the grounds for reflection. This is based on his analysis of the limits of reason and experience separately, vis-à-vis human knowledge. It is only under the influence of custom that together reason and experience are brought to bear upon and reflect on a particular situation that is the foundation of our most valid inferences and conclusion. ${ }^{1}$

Based on Hume's analysis, it is clear that reflective reason by itself cannot account for any knowledge that we have about the world, unless there is repeated experience to aid our inferences. On the other hand, experience by itself cannot give us any necessary connection between occurrences. This relation of necessary connection can only be inferred and theorised on by a reliance on the principle of custom. Reasoning from custom allows us a position of reflection on the continuity in our experiences, as the expectation in the like results from like experiences stems not from reason but custom and experience serving as the grounds for such expectation. Hume categorically states that custom is a fundamental principle of human nature and it is only pretence on our part when we maintain that when we employ custom we have not articulated an ultimate principle (Hume, 1979, p. 43). This principle also serves as the grounds for experiment, as custom is what accounts for sustaining continuity in our actions or engagements with the world. Without the intervention of this principle, we would be limited to our present memory and senses alone. The ability, therefore, to hypothesise and witness its affirmation in the world with an experiment is possible only by relying on custom, whether in the scientific realm or in the social-political.

Hume's formulation of habit or custom covers largely its epistemic influence on human knowledge. However, he briefly remarks on the metaphysical basis of this principle as well, when he says:

[A]s this operation of the mind, by which we infer like effects from like causes, and vice versa, is so essential to the subsistence of all human creatures, it is not probable, that it could be trusted to the fallacious deductions of our reason, which is slow in its operations; appears not, in any degree, during the first years of infancy; and at best is, in every age and period of human life, extremely liable to error and mistake. It is more conformable to the ordinary wisdom of nature to secure so necessary an act of the mind, by some instinct or mechanical tendency, which may be infallible in its operations, may discover itself at the first appearance of life and thought, and may be independent of all the laboured deductions of the understanding. As nature has taught us the use of our limbs without giving us the knowledge of the muscles and nerves, by which they are actuated; so has she implanted in us an instinct, which carries forward the thought in a 
correspondent course to that which she has established among external objects. (Hume, 1979, p. 55).

In line with Hume's indication of the metaphysical basis of the principle of habit, Félix Ravaisson in his seminal text, Of Habit (2008), carries out his enquiry into the fundamental nature and role of habit within the intersection of epistemology and metaphysics. Ravaisson's articulation of habit presupposes a nondualistic conception of nature and the spirit as opposed to the Cartesian dualism of mind and the world. This conception places the will and the freedom associated with it at one end or at the limit of a continuum that extends to the other end of the deepest corners of nature; ${ }^{2}$ and habit is that middle term or the dividing line that constantly traverses by imperceptible degrees this continuum from the limits of these two extremes and enables a relationship between the two. The two ends of this continuum maybe conceived as contraries only in abstraction but through the movement of habit they actually come together.

The body, as the site of this relationship, in this discourse is not a mechanistic or purely material entity. It is in its very being fused and animated by the soul and habit is that principle or law that enables the manifestation of this relationship. To clarify further, Ravaisson does differentiate between the organic and the inorganic realms, ${ }^{3}$ but for him nature also falls within the realm of the organic. Then the primary distinction between the organic and the inorganic is based on the difference between the actuality and potentiality of the former, which provides for habit to take hold in it. Also, that the inorganic resolves into homogeneity and is infinitely divisible whereas the organic is heterogeneous and indivisible. ${ }^{4}$ Despite these distinctions, inorganic existence is presupposed as the condition of organic life and therefore the difference between the organic and inorganic is one of degrees and not absolute which is a crucial point in terms of the relation between the self and the world.

His metaphysics is similar to that of Leibniz's, where each single unity is unique and has its own potentiality and this potentiality cannot be altered from the outside. Another important aspect of Ravaisson's relation with Leibniz is his interpretation of Leibniz's principle of inertia, which is different from the Newtonian articulation of the principle. According to Leibniz, each body persists in the sequence of changes initiated by it. Thus, inertia is not a passive state of a being but an active or dynamic state through which the being tries to persevere in its state. This law is the basis on which Ravaisson shows that habit is not devoid of intelligence despite the fact that it has left the sphere of the active will. The change is initiated by the will and habit carries on with the action, based on the goals set by the will even though there is no immediate consciousness of the same. The difference between will and nature is covered by habit in a continuous flow of imperceptible degrees and not in leaps. This allows Ravaisson to argue against the mechanistic conception of habit as well as the body, as intelligence and reflection do not remain confined to the disembodied thought but pervade the entire being in its concreteness in space and time (Carlisle \& Sinclair, 2008, p. 13).

According to Ravaisson habit functions under a double law, which states that:

The continuity or the repetition of passion weakens it; the continuity or repetition of action exalts and strengthens it. Prolonged or repeated sensation diminishes gradually 
and eventually fades away. Prolonged or repeated movement becomes gradually easier, quicker and more assured. Perception, which is linked to movement, similarly becomes clearer, swifter and more certain. (Ravaisson, 2008, p. 49)

This double law of habit accounts for the diminishing of sensations from a repeated activity on the one hand and the development of skill on the other. For instance, Ravaisson argues that one tends to become immune over time, even to the effects of the most violent poisons when regularly administered (Ravaisson, 2008 , p. 63). In the case of skill, the spontaneity and ease of action is only a manifestation of the will and reflection having become the very nature and flesh of the being. This manifestation of skill, so critically tied up with the body, can be witnessed in the dexterity and works of a craftsperson or an artist or a sportsperson and even in theoretical undertakings of a researcher.

There is a dialectic that is orchestrated by the self/soul that initiates the direction of habit, whether it is towards mechanical repetition or voluntary action. It is in the movement of the body that the will and intelligence of the being are manifested. Habits in this sense are signs that instantiate the relation between the self and the world. It is also in this context that the concept of labour takes on its relevance, as it not only accounts for the individual in isolation but in his relation with others as well as nature. The movement of the body that manifests the will and intelligence of the self comes on to take a clearly etched aspect in terms of man in his relationship with the other and the body politic in the form of the body in labour. Thus, the body in movement, as revealed via habit, is crucial as grounds to the extension of the argument that the body in labour can be conceived as the sign of human identity and essence.

Articulated as such, the body in labour is the site of not only the self and the world mediating but also the private and the public. Engels in his essay, The Part Played by Labour in the Transition from Ape to Man (1996) articulates the fundamental role of labour as a repeated activity that allowed for the evolution of man. He states that labour is so primary to being the basic condition for human existence, that it can be said that labour created man (Engels, 1996, p. 1). His argument rests primarily on the role of the human hand, which is not only an instrument of labour but also, attained its own form and dexterity via its repeated use over generations. ${ }^{5}$ Thus, labour as the repeated activity plays a fundamental role in establishing man as distinct from other animals. Engels argues for this by saying that no animal, however similar structurally its hand may be to man, but it was never able to fashion even a crude tool (Engels, 1996, p. 2). The role of repetition is significant in the development of man's dexterity and in the development of his own identity in distinction from animal life.

However, in Engels' materialist discussion of the body and labour, the role played by the self and reflection is not discussed. Marx elaborates this aspect more clearly and comprehensively and in some distinction from Engels, when he states that truly human labour is not merely a means of livelihood or survival but in fact it is truly human when production occurs free from the bodily needs of man. Animals also engage in production and in that sense labour as well, however, the difference is that man produces not just for his own self or his species but taking into account all of nature, that is, he produces universally (Marx, 2009, 
p. 32). This formulation by Marx brings into focus the significance of the self and knowledge into labour as an activity undertaken by man to affirm and instantiate his humanity as opposed to being a mere repetition or purely mechanical activity. The labour that Marx speaks of takes account of the essence of humanity and distinguishes humans from animals as opposed to being a repetitive movement. ${ }^{6}$

The habits of a person are not developed in isolation, but are part of his social nature. In the context of labour, Marx states that it reaffirms the species-being of man. In the context of habit formation, John Dewey (1923) states that it is customs that take precedence over individual habit formation as each individual is born into a society, which is conditioned by prior customs, and individuals accommodate themselves to these customs. He further states that:

Each person is born an infant, and every infant is subject from the first breath he draws and the first cry he utters to the attentions and demands of others. These others are not just persons in general with minds in general. They are beings with habits, and beings who upon the whole esteem the habits they have, if for no other reason than that, having them, their imagination is thereby limited. (Dewey, 1923, p. 58)

For an individual to share the life of a community, the customs of that community play an essential role. They are what allow an association between the individuals, the society and the body politic.

Custom, like habit, has been regarded as a deterrent to rational thought. ${ }^{7}$ The primary issue in this regard has been that customs seem to demand unconditional adherence and encourage conformity, thereby thwarting individual freedom and thought. However, this problem emerges based on a misunderstanding of the fundamental nature of custom. This problem presupposes a fossilised and rigid nature of custom. It is empirically observed that rigid customs are detrimental to an individual's freedom and development; however, this is not the nature of custom in principle. The crucial point is that customs indicate the nature of the relation between the individual and the society/body politic. Customs when fossilised indicate an imitative or mechanical relation; however, customs when adaptable and living indicate the role of reflection as the basis of society. There is a dialectic that plays out between a private individual and the public life of a community, which is determined by the interaction of the habits of the individual and the customs of the community. Imitative following of customs by individuals (with specific habits) leads to stagnation of the community and thwarting of individual freedom, on the other hand individuals (also with specific habits) who participate in their tradition and customs with a reflective understanding may allow maturity and growth of both the community and the self. The underlying principle to this view is one of continuity. This world-view presupposes that changes, specifically in terms of the social and political sphere, do not take place in leaps. The social and the political sphere is so deeply embedded within the traditional and the circumstantial that to effect any sense of change within this realm first requires submission to the tradition and thereby a careful knowledge of it and only then a retention or improvement from within. ${ }^{8}$ This formulation lays the grounds for the coming together of experience and reflection in the social and political sphere, which further allows for the possibility of experiment within this sphere. ${ }^{9}$ 
In fact, customs as such cover almost the entire range of activities in our livesfrom the clothes we wear to how we know and understand our world. Ravaisson calls habit, the 'law of grace' (Ravaisson, 2008, p. 57), and this designation is also applicable to custom. Custom is the principle that prevents us from exerting away at each and every detail of our lives and allows us to participate in the collective inheritance of the community with ease. ${ }^{10}$ The validity of this principle and its influence in human lives presupposes interrelatedness, that is, individual existence presupposes as its very basis the existence of other beings.

\section{Conclusion}

There is a complex and continuous dialectic that plays out between the individual, nature and his community, each of which interact and affect each other. In the sense that nature provides the material conditions to which societies and individuals respond. It determines the limits of their customs and habits. On the other hand, it is also the individuals who wilfully orchestrate the direction of their habits, which go on to affect the community as well as nature. However, as Ravaisson argues that by analogy the cosmos/nature itself can be viewed as pervaded by a certain kind of intelligence or will. This 'will' is manifested in the regular laws of nature, in nature's spontaneity, where the idea and the being are always fused together. In this way, the principle of habit pervades not only the human being but also the cosmos. And it is the principle of habit that enables a relation between the individual and the world or the microcosm and the macrocosm.

All these relations draw on the body as its pivotal site. It is clear that the body in this discourse cannot be limited to the immediate self, neither epistemically nor ontologically. The body is constituted and understood as the ground for dialectic between the personal and the impersonal in terms of man and nature and the private and the public in terms of the individual and the body politic. Metaphysically, the logical conclusion of this is that the personal or the immediate body is just one aspect of the self and the other aspect of the impersonal body in its fundamental constitution (habits and patterns of interaction) can take account of the deepest corners of the cosmos and in terms of the body politic, even the most distant member.

\section{Acknowledgement}

I am grateful to Dr Anuradha Veeravalli for her comments on an earlier draft of this article which helped in formulating its structure.

\section{Notes}

1. For examples and a detailed exposition of this position, see Hume (1979), particularly note pp. $43-45$. 
2. This dualism is couched in the apparent antinomy of voluntary freedom and natural necessity, and habit is the principle that allows this to be surmounted (Carlisle $\&$ Sinclair, 2008, p. 103). For Ravaisson, this dualism is a matter of distinction as opposed to separation, as he goes on to argue that the difference between the two realms is not absolute but a matter of degrees.

3. The organic realm is the empire of Nature and the inorganic is the empire of Destiny (Ravaisson, 2008, p. 31).

4. These distinctions are further based on the difference of organisational structure between organic and inorganic existence. Within inorganic existence, there is homogeneity and therefore little scope for habit to transform which leads to necessity. On the other hand, organic existence indicates heterogeneous unity within space and therefore a difference in actuality and potentiality, that allows for habit to transform the being and allows for spontaneity. For habit presupposes change, but a change that repeats itself and thereby acquires a certain kind of persistence. This change is not within the inherent potentiality, which is the limit of the change, but in the actuality. It is this persistence in the actuality that manifests itself as the ground for spontaneity (Ravaisson, 2008, p. 33).

5. Based on the Bible (Saint Paul, Romans, 7:23), Ravaisson also articulates habit as the law of the limbs (Ravaisson, 2008, p. 57).

6. The image from Modern Times (Charlie Chaplin, 1936) comes to mind in this context. The image of the tramp's incessant tics and contorted movements while working in the factory is a good example to distinctly see what Marx means by alienated labour. In the movie, under the regime of the modern factory set-up, the tramp is as such labouring, but one can see the degradation of the self in such a system, which stands further instantiated when the tramp is sent to the mental asylum. However, true labour would actually be just the opposite of this conception. The form of such a labour would actually instantiate man's humanity and wisdom with respect to being able to account for production taking account of all of nature.

7. For a discussion on the conception of customs in modern philosophical thought, see Custom (Ladd, 1967).

8. For a detailed discussion of this, see Rationalism in Politics (Oakeshott, 1991).

9. This conclusion can be instantiated through an insight into Gandhi's various socialpolitical experiments, such as with diet and Brahmacharya. Anuradha Veeravalli has discussed these in Gandhi in Political Theory (2014).

10. Dewey presents an analogy to explain the relevance of customs in this context. He says:

Few persons have either the energy or the wealth to build private roads to travel upon. They find it convenient, 'natural', to use the roads that are already there; while unless their private roads connect at some point with the high-way they cannot build them even if they would. (Dewey, 1923, p. 59)

\section{References}

Dewey, J. (1923). Human nature and conduct. New York: Henry Holt and Company. Engels, F. (1996[1934]). The part played by labour in the transition from ape to man. Moscow: Progress Publishers. Retrieved 28 February 2017, from https://www. marxists.org/archive/marx/works/1876/part-played-labour/ 
Hume, D. (1979). Enquiries concerning human understanding and concerning the principles of morals. L.A. Selby-Bigge and P.H. Nidditch (Eds). Oxford: Oxford University Press.

Ladd, J. (1967). Custom. In Paul Edwards (Ed.), The encyclopedia of philosophy (pp. 277-278). New York: Macmillan.

Malabou, C. (2008). Addiction and grace: Preface. In F. Ravaisson (Ed.), Of habit (pp. vii-xx). London: Continuum.

Marx, K. (2009 [1959]). Economic and philosophic manuscripts of 1844. Moscow: Progress Publishers. Retrieved 28 February 2017, from https:/www.marxists.org/ archive/marx/works/download/pdf/Economic-Philosophic-Manuscripts-1844.pdf

Merleau-Ponty, M. (1962). Phenomenology of perception (trans. Colin Smith). London: Routledge and Kegan Paul.

Oakeshott, M. (1991). Rationalism in politics. In M. Oakeshott (Ed.), Rationalism and politics and other essays (pp. 5-42). Indianapolis, IN: Liberty Fund.

Ravaisson, F. (2008). Of habit (trans. Clare Carlisle and Mark Sinclair). London: Continuum.

Veeravalli, A. (2014). Gandhi in political theory. Farnham, Surrey, UK: Ashgate. 